\title{
Evaluation of the pair-culture effect in Ophryotrocha puerilis (Polychaeta: Dorvilleidae). I. Pair-culture effect and sex ratio
}

\author{
B. Kegel* \& H.-D. Pfannenstiel \\ Institut für Allgemeine Zoologie, Freie Universität Berlin; Königin-Luise-Str. 1-3, \\ D-1000 Berlin 33, Federal Republic of Germany
}

\begin{abstract}
Pairs and larger groups of female Ophryotrocha puerilis puerilis were formed from formerly isolated specimens. Neither the diameter of the oocytes present in the coelomic fluid nor the number of setigerous segments (ss) of the partners of a newly formed pair allow us to predict which one of the two animals will exhibit sex reversal. Amputation of the palps showed that these ventrolateral appendages of the prostomium are not responsible for the transmission of the mutual influence which is exerted during the pair-culture effect. Isolated females do not produce egg masses but keep their oocytes in the body cavity until they are eventually resorbed. The shedding of oocytes in one of the females of a newly formed pair was formerly considered to be the first step in the pair-culture effect. The present results demonstrate that egg laying in these cases is unspecific and due rather to the end of isolation than to specific interactions with the partner. In groups consisting of up to 50 animals the sex ratio oscillates around $1: 1$. The presence of primary males does not influence the sex ratio of adult specimens, although these males are capable of fertilizing egg masses produced by adult females. As a result, a high percentage of both young and old males are found in densely populated bowls. The significance of the pair-culture effect in natural populations is discussed in the light of these findings.
\end{abstract}

\section{INTRODUCTION}

Both Ophryotrocha puerilis siberti from the Atlantic and $O$. puerilis puerilis from the Mediterranean are consecutive hermaphrodites (for review see Bacci, 1965; Pfannenstiel, 1978). Young worms become sexually mature as males. At a length of about 16 setigerous segments (ss), sex reversal occurs and oogenesis is continued in isolated individuals to the end of their life span. When two formerly isolated females happen to meet, one of them will resorb or shed its oocytes and restart spermatogenesis. During this pair-culture effect, which was described by Hartmann and his co-workers (1936-1942), the primitive type upper jaw is replaced by the complicated upper jaw in the sex reverting partner. Müller (1962) showed that direct contact of the partners is necessary in order to ensure the mutual influence. Further investigations (Pfannenstiel, 1973a, 1975, 1977) led to the assumption that the palps act as transmitters of some sort of pheromone. Since the regular switch from male to female differentiation is hormonally mediated by

* Present address: Institut für Bỉologie der Technischen Universität Berlin; Franklinstr. 28/29, D-1000 Berlin 10, Federal Republic of Germany 
the prostomium (Pfannenstiel, 1973a), the pheromone was thought to act via the endocrine system. The pair-culture effect has always been understood as a reproductive strategy which leads to fertile couples whenever two individuals meet. Previously, experiments were carried out under conditions which did not resemble natural conditions at all, although it is known that very dense populations of $O$. puerilis are found in the natural habitat. The aim of the present study was to repeat experiments of Pfannenstiel (1975) and to design experiments, the conditions of which were more likely to represent the natural situation.

\section{MATERIALS AND METHODS}

The specimens used for this study were taken from laboratory cultures. The cultures originated from specimens of Ophryotrocha puerilis puerilis which were collected at Livorno (Italy) in 1974. The culture methods have been described elsewhere (Pfannenstiel, 1973b). The animals used for the experiments were raised in isolation. They were fed spinach during growth. Specimens employed in amputation experiments were not fed. Sex and number of ss were recorded at regular intervals without anaesthetizing the experimental animals. Amputation of the palps was carried out on anaesthetized specimens (6\% magnesium chloride in distilled water). Controls and intact partners of operated worms were anaesthetized for the same length of time. During the 14-day observation period the palps regenerated in many cases and had to be removed for a second or even third time.

\section{RESULTS}

\section{Isolated individuals}

Sexual differentiation was recorded in 35 isolated specimens. At a length of 7.9 ss (5-11), spermatozoa were found in the coelomic cavity. All 35 animals changed sex at 15.2 ss (12-18) and became females. The mean number of segments at which worms switch from the male to the female phase as well as the number of segments at which sexual maturity is reached varies to a considerable extent in populations of different geographical origin (for review see Åkesson, 1983).

\section{Pair-culture}

When isolated females $(n=62)$ were taken for pair-cultures, $74 \%$ of the pairs $(n=23)$ showed the normal sequence of events characteristic for the pair-culture effect. Within the 3-week observation period, $53 \%$ of the male partners changed their upper jaw. In earlier experiments (Pfannenstiel, 1975), almost all pairs showed the pair-culture effect and almost all the males in these pairs replaced their primitive upper jaw by the definitive upper jaw. We think that the differences observed are due to the fact that animals of different geographical origin were taken for the earlier experiments.

In another series of experiments, females with different numbers of ss or at different stages of oogenesis formed couples. Out of 50 pairs with pair-culture effect an almost equal number of smaller partners $(n=27)$ and bigger partners $(n=23)$ showed sex 
reversal to the male state. Out of 26 pairs, the partners of which showed different stages of oocyte development at the beginning of the experiment, 16 specimens with almost fully grown oocytes (100-130 $\mu \mathrm{m}$ in diameter) and 10 females with small oocytes (30-60 $\mu \mathrm{m}$ in diameter) switched back to the male state. The results of these experiments indicate that neither the length nor the stage of oocyte development of a female determine whether or not sex reversal will occur.

Pfannenstiel (1977) qualified the palps as transmitters of a stimulus responsible for the pair-culture effect. In order to obtain further evidence for this assumption, two different types of amputation experiments were performed (Fig. 1). In newly formed pairs ( $\mathrm{pcn}$ ) the palps of one female were amputated, while the other female remained intact. In 23 pairs $(68 \%)$ out of 34 pairs a normal pair-culture effect was observed. In
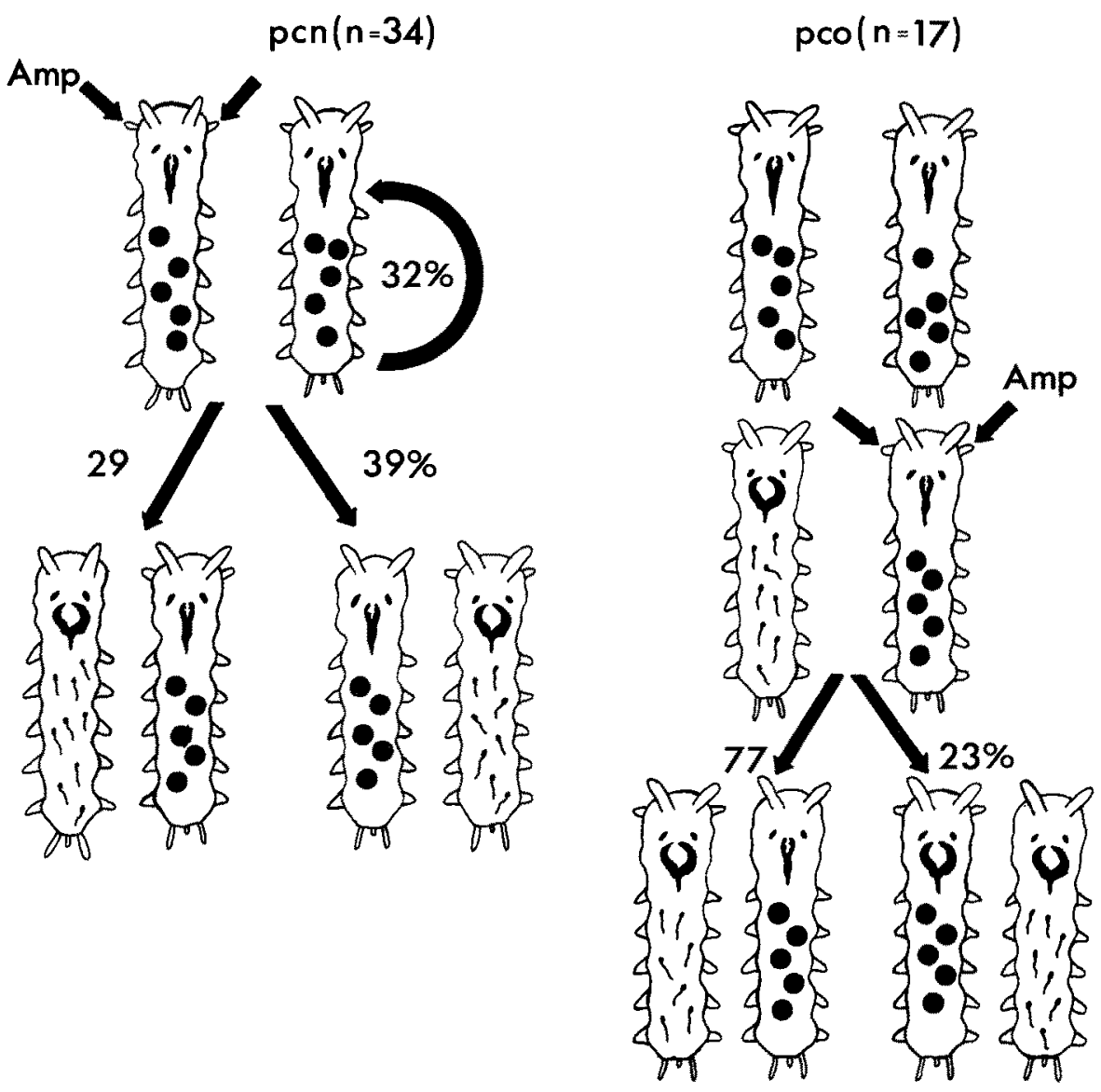

Fig. 1. Ophryotrocha puerilis; pcn = newly formed pairs; Amp = palps of one female were amputated; in $32 \%$ of the pairs the partners did not change sex; in $64 \%$ of the pairs sex reversals occurred ( $29 \%$ of the palpless specimens switched to males while $39 \%$ of the palpless specimens remained females); pco $=$ pairs of formerly isolated females; Amp = palps of females were removed in couples exhibiting the pair-culture effect; in $77 \%$ of the experimental couples no sex reversals occurred; in $23 \%$ the palpless partner became male 
$29 \%$ of these pairs the operated partner without palps became male. In $39 \%$ of the couples the females without palps remained in the female state. $56 \%$ of the secondary males replaced their primitive jaw by the complicated one. The complicated jaw was developed at the same rate in both intact and operated specimens. In a control experiment both partners of a couple remained intact. Out of 22 of these controls, 17 couples $(77 \%)$ showed the pair-culture effect. $65 \%$ of the secondary males in control couples developed the complicated jaw. In a second type of experiment (pco, Fig. 1) couples were formed out of formerly isolated females. The palps of the females were removed in such couples which exhibited the pair-culture effect $(n=17)$. In control pairs both males and females remained intact. During the observation period of 14 days, $23 \%$ of the experimental pairs $(n=4)$ and $15 \%$ of the control pairs $(n=2)$ showed simultaneous sex reversals in both partners of a pair. The results of experimental and control pairs are essentially the same and indicate that the palps are not responsible for the transmission of the mutual influence during pair-culture. Also, removal of the palps in isolated females did not interfere with sexual differentiation.

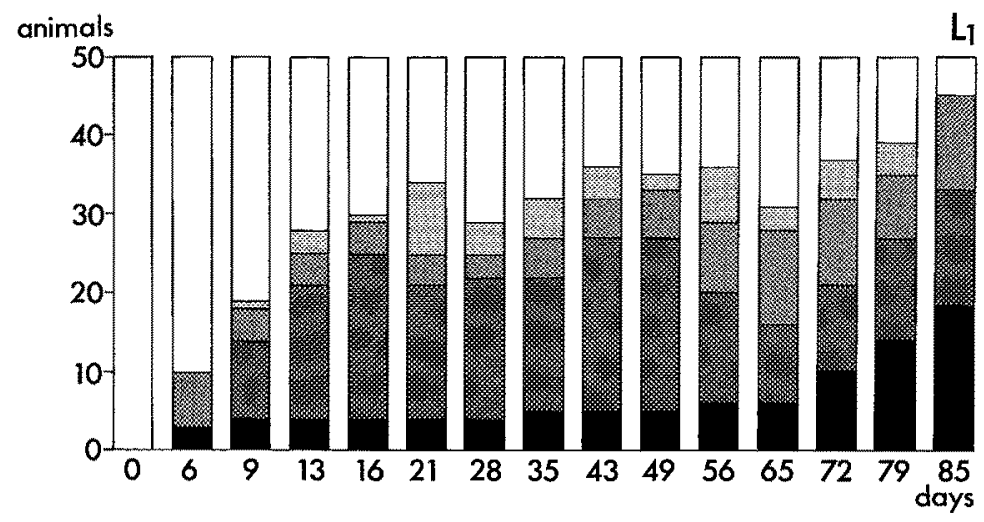

Fig. 2. Ophryotrocha puerilis; $\mathrm{L}_{1}$ - development of sex ratio in a group of 50 formerly isolated females; for further explanations see text and Fig. $4 \mathrm{~b}$

\section{Groups of 25 or 50 specimens}

In the experiments described, groups of $25\left(\mathrm{XXV}_{1}-\mathrm{XXV}_{3}\right)$ or $50\left(\mathrm{~L}_{1}-\mathrm{L}_{3}\right)$ formerly isolated females were formed in order to follow the male/female ratio in a more natural situation. The oocytes shed by females in the course of these experiments were removed from the bowls at frequent intervals. Due to the fact that animals are very aggressive after a period of isolation, mortality in some of the experimental groups was very high. Figure 2 represents the data of group $L_{1}$. The high number of specimens containing both oocytes and sperm indicate that sex reversals occurred in both directions throughout the observation period of 3 months. In all the groups secondary males were found 5 to 7 days after the groups had been established (Figs 2,4). Figure 3 represents sex ratio changes in the XXV and in the L groups. Between day 10 and day 30 the number of secondary males reached its maximum. Thereafter, the number of females was found to increase again at the expense of males. From now on sex ratio in the different groups was found to oscillate 

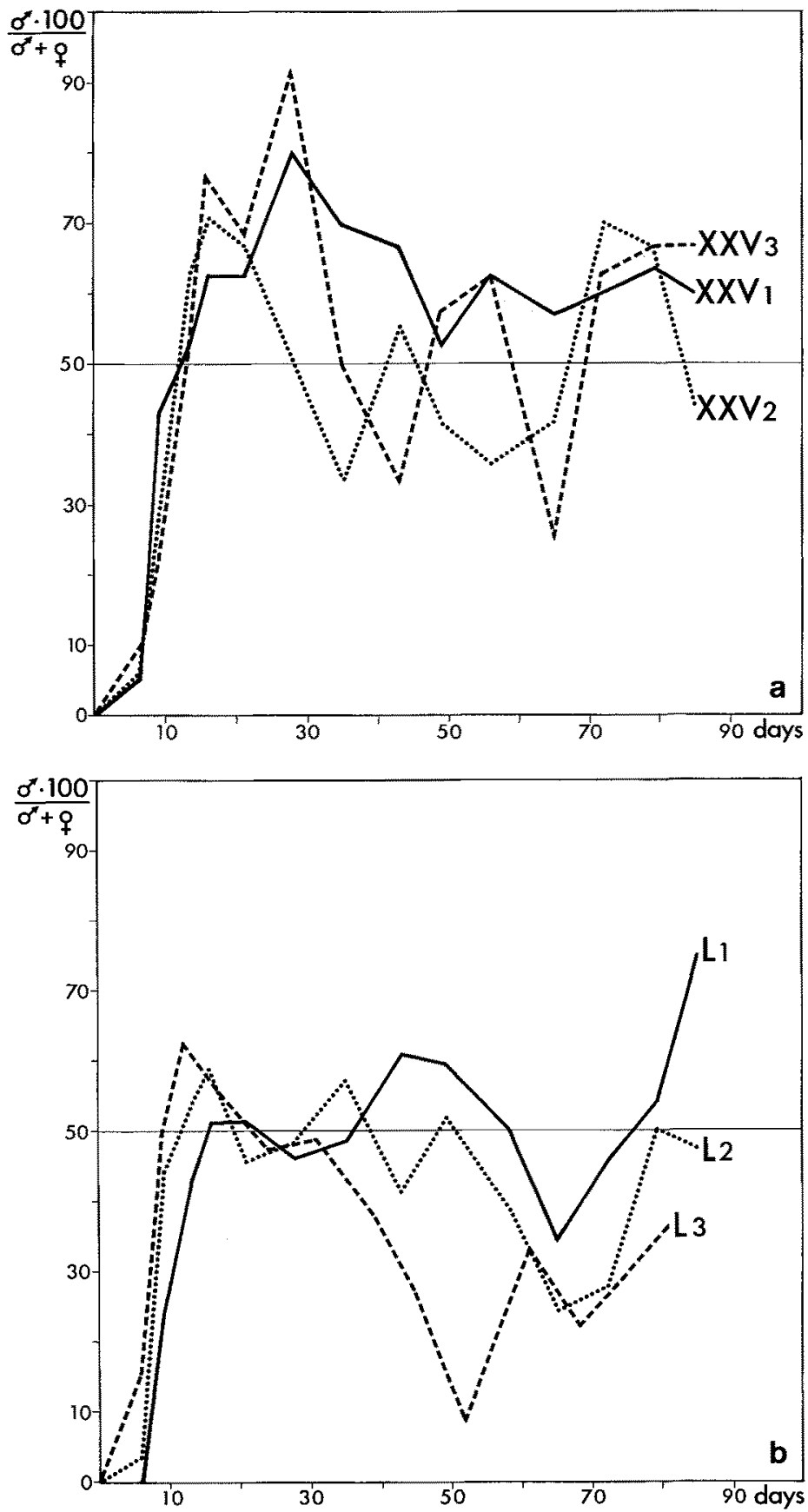

Fig. 3. Ophryotrocha puerilis; $\mathrm{a}=$ development of sex ratio in 3 independent groups of formerly isolated females each group consisting of 25 specimens; $\mathrm{b}=$ development of sex ratio in 3 independent groups of formerly isolated females each group consisting of 50 specimens 


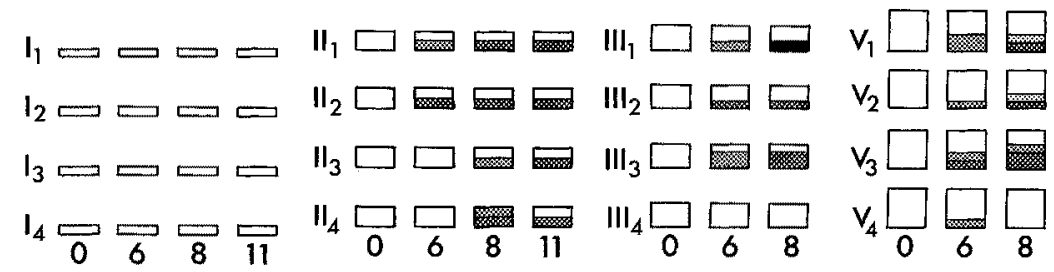
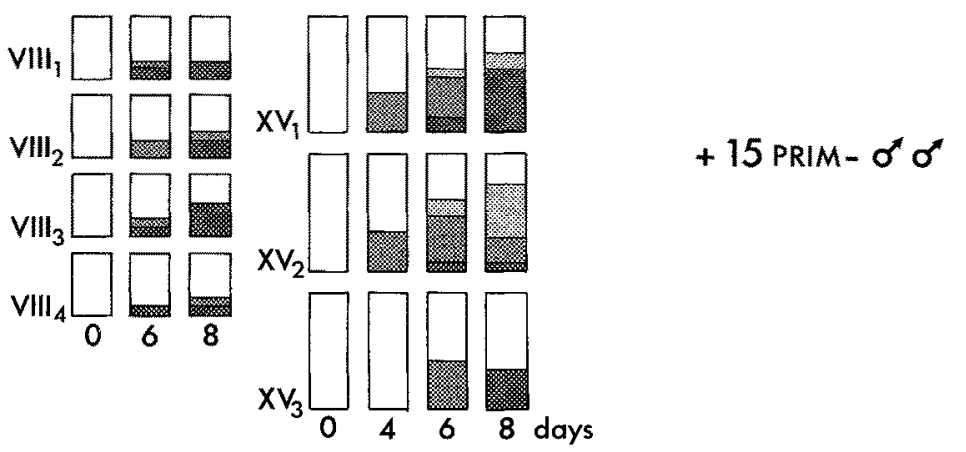

+15 PRIM $-\sigma \sigma$

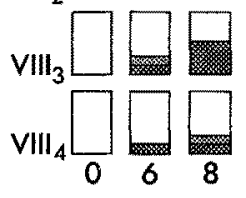

a
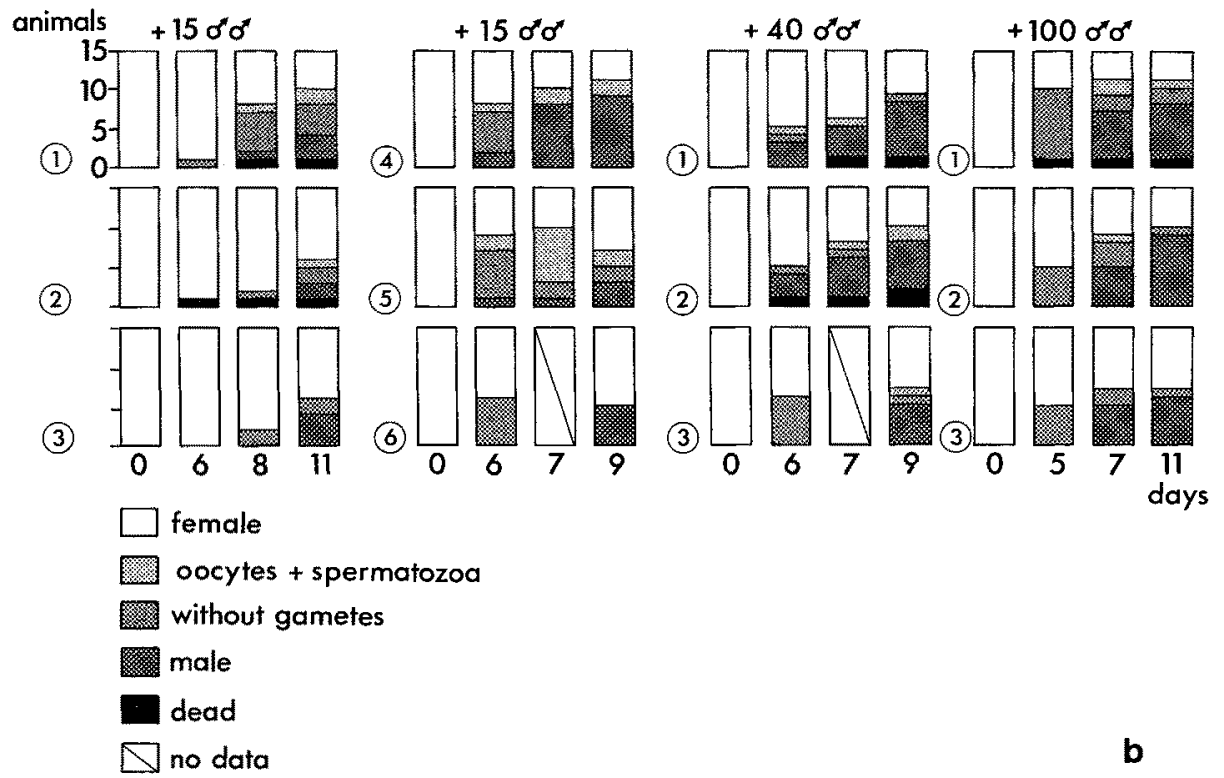

Fig. 4. Ophryotrocha puerilis; influence of primary males on sexual differentiation in adult specimens; $a=I_{1}-I_{4}-1$ isolated female was combined with 15 primary males in each of the 4 experiments; $\mathrm{II}_{1}-\mathrm{II}_{4}-2$ isolated females were combined with 15 primary males in each of the 4 experiments; read III, V, VIII and XV, respectively; $\mathrm{b}=$ groups of 15 formerly isolated females were combined with 15 primary males (6 experimental groups), with 40 primary males ( 3 experimental groups) or with 100 primary males ( 3 experimental groups), respectively 
around $1: 1$ in a very similar way. The amplitudes of these oscillations have been found to be positively related to the initial number of secondary males.

In another series of experiments, different numbers of formerly isolated females were combined with different numbers of primary males. The oocytes shed by females were removed from the culture vessels at frequent intervals. The results of these experiments are compiled in Figure 4 . Regardless of the number of primary males, the adult females showed sex reversals (after 5-7 days) the number of which ensure a statistically $1: 1$ sex ratio in adults. The experiment shown in Figure 5 yielded an even more striking result. In this case the oocytes released by females were not removed. The newly forming secondary males fertilized the eggs. As a result hundreds of young were growing up together with their parents becoming primary males within the observation period. However, the adults did not change their 1:1 sex ratio initially developed.

In groups of formerly isolated females, spontaneously released oocytes are usually found only a few minutes after formation of a group. In the absence of males these

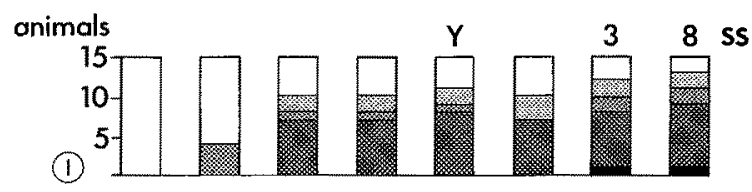

(2)

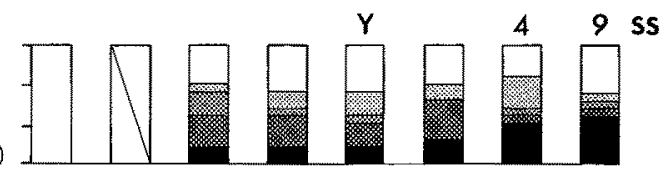

(3)

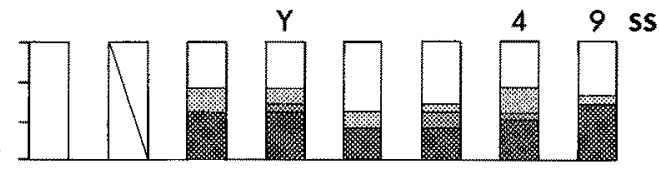

(4)

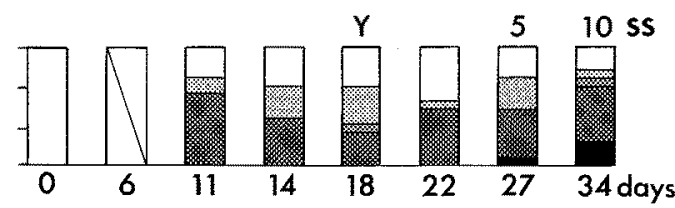

Fig. 5. Ophryotrocha puerilis; in four experimental groups (1-4) 15 formerly isolated females were grouped and kept together with their growing offspring; $Y$ - first observation of newly hatched young; number of ss (setigerous segments) give average sizes of growing young 
oocytes are not fertilized but degenerate. If primary males are present the oocytes released by adult females are fertilized by these young males.

These results indicate that (a) primary males are fertile although they do not influence the sex ratio found in adult specimens, (b) in natural populations with animals of all developmental stages and randomly distributed ages males must be present in much greater numbers than females, and (c) the initial release of oocytes in pairs or groups is not related in a specific way to the pair-culture effect but rather represents a reaction to the cessation of isolation.

\section{DISCUSSION}

The pair-culture effect in Ophryotrocha puerilis has always been understood as a strategy of reproduction which leads to a fertile pair whenever two individuals meet. Three components have been thought to constitute the pair-culture effect (Pfannenstiel, 1975): shedding of oocytes, replacement of the p-jaw by the $k$-jaw and finally sex reversal in one of the partners. The present results make it necessary to reevaluate the phenomenon as such and its significance for the reproductive success of the species. The release of oocytes in formerly isolated females represents an unspecific reaction to the end of isolation rather than being a significant part of the pair-culture effect. On the other hand, the formation of the definitive upper jaw (k-jaw) has been observed in both pairs and isolated individuals (Kegel \& Pfannenstiel, 1983). Consequently, the specific and significant event of the pair-culture effect is the change of sex in one individual. In the unnatural situation of a pair, sex reversal in one partner is not observed at all in $100 \%$ of the cases. Therefore, the present authors think that the pair-culture effect performed by only two individuals is an unphysiological expression of a much more complex phenomenon normally acting on the population level and regulating the male/ female ratio in natural populations in order to maximize the reproductive success.

Life cycle theorists have asked the question why labile sex determination was not replaced by simple chromosomal mechanisms during evolution. According to Charnov \& Bull (1977), selection favours environmentally influenced sex determination when the progeny enters an environment which has a large effect on its overall fitness and where neither parents nor offspring have control over the type of environment the young will enter. In the case of a consecutive hermaphrodite like $O$. puerilis the possibility of changing sex as an adult implies the chance for a whole population to manipulate the overall sex ratio according to the environmental conditions the population faces at the very moment. If conditions are favourable for oogenesis, more females are found and only a few males. When female expenditure during oogenesis becomes too expensive due to harsh conditions (starving conditions) it pays off to be a male. The pair-culture effect in Ophryotrocha puerilis most likely represents the physiological basis for the adjustment of the sex ratio in natural populations. The palps have been eliminated as candidates for transmitting the mutual stimulus. It still remains unknown how the mutual influence is exerted during the pair-culture effect.

Acknowledgement. This work was supported by FPS “Adaptive Dynamik in Struktur und Leistung tierischer Organe", FU Berlin. 


\section{LITERATURE CITED}

Akesson, B., 1983. Speciation in the genus Ophryotrocha (Polychaeta, Dorvilleidae). - Fortschr. Zool. (In press).

Bacci, G, 1965. Sex determination. Pergamon Press, Oxford, $306 \mathrm{pp}$.

Charnov, E. L. \& Bull, J., 1977. When is sex environmentally determined? - Nature, Lond. 266, 828-830.

Hartmann, M. \& Huth, W., 1936. Untersuchungen über Geschlechtsbestimmung und Geschlechtsumwandlung bei Ophryotrocha puerilis. - Zool. Jb. (Allg. Zool. Physiol. Tiere) 56, 389-439.

Hartmann, M. \& Lewinski, G. von, 1938. Untersuchungen über die Geschlechtsbestimmung und Geschlechtsumwandlung von Ophryotrocha puerilis. II. Versuche über die Wirkung von Kalium, Magnesium und Kupfer. - Zool. Jb. (Allg. Zool. Physiol. Tiere) 58, 551-574.

Hartmann, M. \& Lewinski, G. von, 1942. Untersuchungen über die Geschlechtsbestimmung und Geschlechtsumwandlung von Ophryotrocha puerilis. III. Die stoffliche Natur der vermännlichenden Wirkung "starker" Weibchen ("Eistoffe"). - Zool. Jb. (Allg. Zool. Physiol. Tiere) 60, $1-12$.

Kegel, B. \& Pfannenstiel, H.-D., 1983. Evaluation of the pair-culture effect in Ophryotrocha puerilis (Polychaeta: Dorvilleidae). II. Conditions for the moult of the upper jaw. - Helgoländer Meeresunters. 36, 215-222.

Müller, H., 1962. Uber die Sexualität des Polychaeten Ophryotrocha puerilis, ihre Determination und ihren Einfluß auf Drüsentätigkeit und Kauapparatentwicklung. - Z. Morph. Okol. Tiere 52, $1-32$.

Pfannenstiel, H.-D., 1973a. Zur sexuellen Differenzierung von Ophryotrocha puerilis (Polychaeta: Eunicidae). - Mar. Biol. 20, 245-258.

Pfannenstiel, H.-D., 1973b. Der Meeresborstenwurm Ophryotrocha puerilis. Ein ideales Labortier. Mikrokosmos 62, 97-100.

Pfannenstiel, H.-D., 1975. Mutual influence on the sexual differentiation in the protandric polychaete Ophryotrocha puerilis. In: Intersexuality in the animal kingdom. Ed. by R. Reinboth. Springer, Berlin, 48-56.

Pfannenstiel, H.-D., 1977. Experimental analysis of the "Paarkultureffekt" in the protandric polychaete Ophryotrocha puerilis Clap. Mecz. - J. exp. mar. Biol. Ecol, 28, 31-40.

Pfannenstiel, H.-D., 1978. Endocrinology of polychaete reproduction and sexual development. Boll. Zool. 45, 171-188. 